\title{
Diversification in the Academic Workforce: The Case of the US and Implications for Europe
}

\author{
MARTIN J. FINKELSTEIN \\ Seton Hall University, USA. E-mail: finkelma@shu.edu
}

This paper examines two broad dimensions of change in the American academic profession: (1) demographic and generational change, including increasing feminization, changing attitudes toward the career-family balance, migration of faculty positions to the professions (versus the liberal arts) and away from the research university sector; and (2) changes in types of appointments, work and career tracks, including the decline of tenure and the rise of fixed term appointments, which involve more 'specialized' and less 'place-bound' work roles and alternative career tracks. It considers these changes more broadly in the context of the changing nature of work in a globalized economy and the changing nature of the knowledge industry and in the context of similar developments in Europe and Asia. It concludes with an extrapolation of how these trends are likely to play out in the US context and in a new 'globalized' academic marketplace over the next 10-20 years.

\section{Introduction: The basic thesis}

This paper advances a simple basic thesis: what has heretofore been a relatively homogeneous corps of professionals - in terms of their demographics (who they are), their work role (what they do), the locus of their work activities (where they work and their time and place boundedness), their career exclusivity or preemptiveness (the place of academic work in their 'lifespace') and the structure of their career track (the rungs of their career ladder) - has in the space of a generation or two morphed into a patchwork of relatively distinctive and fragmented workforces, each with its own demographic profile, work and career 
profile. Any discussion of the academic workforce in the US today must now recognize this diversification and speak in a nuanced way about segments and their relative pre-emptiveness rather than hazard generalizations about some amorphous - and now mythic - whole.

\section{Demographic change}

Consider the following changes in the profile of faculty supply in the US in barely two generations.

\section{Gender and marital status}

Four of five faculties in 1969 were men and new recruits barely differed from old hands. By the early 2000s, nearly $2 / 5$ faculty are women overall, and, among new recruits, the gender ratio is approaching 50:50. While earlier generations of academic women were predominantly single, the new generation is married, have children and, more often than not, are part of a dual career couple. ${ }^{1}$

\section{Race/ethnicity}

In 1969, 9/10 full-time faculty were Caucasian (and mostly male). By 2004, the overall figure had shrunk to $8 / 10$ and lower among the newest recruits.

\section{Nationality}

In 1969 , barely $10 \%$ of the faculty were foreign-born, typically of European origin - refugees from Nazi Germany or the old Soviet Union. The vast majority are now of East Asian (Chinese) or South Asian (Indian) origin with very different orientations to work than their native born counterparts. Especially among new recruits in the natural sciences, mathematics and engineering, perhaps as many as a quarter to a half are foreign born Asians. And unlike native born faculty, this group is disproportionately male. While the behaviour of these foreign nationals is shaped by labour market conditions in the United States, it is also being shaped by new economic developments and labour market conditions in their native countries - a new 'wild card' factor. As nations such as China, South Korea and, to a lesser extent, India, have initiated major investments in their developing higher education systems to build 'world-class' universities, conditions of academic life and prospects for academic careers are improving quickly and substantially - providing newly competitive opportunities for pursuing academic careers and precipitating an incipient 'reverse brain drain'.

\section{Generational Weltanschauung}

In 1969, the American faculty was dominated by members of the Second World War generation and the newest recruits were members of the Baby Boom generation. 
Today, it is the baby boom generation that is retiring, being replaced by Generation Xers and members of the Millennial generation. ${ }^{2}$ This latter is a generation focused more self-consciously on family and work-life balance issues, on teamwork and service in the name of the greater good.

\section{Changing institutional and professional profile}

Consider at the same time these shifting axes of demand for faculty in the US.

\section{Academic field}

In 1969 , more than $2 / 3$ faculty were in the traditional arts and sciences disciplines pursuing their graduate education and their early career in perfect lockstep pattern. By the early 2000s, the disciplinary balance had radically shifted towards the professional (non-arts) fields, especially the health professions. Among new faculty recruits, the majority are now in the professions - higher and lower - and drawn as frequently from professional practice as from an insular and clearly identifiable pre-service career track.

\section{Institutional venue}

In 1969, about half the faculty were employed in research universities and the remainder distributed, for the most part, over other four-year institutions. Today, the proportion of faculty residing in research universities has shrunk to barely $2 /$ 5 ; and most of the recruitment is being done by other than research universities for other than research roles.

\section{Type of appointment}

In 1969, virtually all faculty positions were full-time, tenure eligible career tracks. Every incumbent was expected to play roughly the same 'integrated' role consisting of teaching, research and service. Beginning with a vengeance in the 1970s, the ranks of part-time appointments swelled. And, beginning in the 1980s, full-time appointees were increasingly routed into fixed-term contract appointments and off the tenure track. Indeed, for at least the last 15 years, the majority of all new full-time hires has been to fixed contract, temporary appointments. These appointments reflect not merely differences in the duration and permanence prospects of contracts, but a re-definition of the work role itself. Contract appointments typically entail more specialized roles - teaching only, research only, programme director only - and often preclude formal involvement in academic governance. ${ }^{3}$

Assessing what these new developments and conditions mean for the future of the American academic professions depends, of course, on the context in which one interprets them: are they temporary dislocations or fallout from an extended academic depression (part of the academic business cycle)? Or, do they represent 
structural re-alignments, that is, the recasting of the academic marketplace in a globalized, knowledge-based economy? Up until quite recently, that matter of interpretation was hardly settled. Bowen and Schuster (Ref. 14) had predicted a widespread supply shortage of the 'best and brightest' when the swelling Baby Boomlet hit college age in the first decade of the 21 st century. Indeed, they seemed to suggest at that time the imminent restoration of the old academic equilibrium of the seller's market of the 1960 s - with an impending rush to create new 'tenure-track positions' and to do away with the lion's share of part-time appointments. Frances had predicted a surge in demand for faculty in response to continuing expansion of traditional student demand - albeit warning of the unpredictable effects of the new digital instructional technologies. ${ }^{4}$ And, most recently, Leslie predicted that widespread retirements of 'Baby Boomer' faculty amid the relative underdevelopment of the 'under 40' junior faculty ranks would cause a crisis in replenishing the faculty. ${ }^{5}$

An increasing consensus, however, is emerging that while tenure and traditional academic appointments are not yet 'dead' ${ }^{6}$ we are witnessing a structural realignment that has little that is temporary about it. Finkelstein ${ }^{7}$ recently invoked Trow's 8 concept of the structural transformation of national systems of higher education (from elite to mass to universal access) to remind us that broader transformations in the economy (industrialization, the emergence of the globalized, knowledge-based economy) have historically driven reconfigurations of higher education and the nature of academic work and careers - at least in the American context. Developments such as feminization of the workforce, globalization of the labour market, the restructuring of work along the lines of greater 'casualization' to ensure competitiveness - reflect larger social forces that are transforming work in America and the world. The restructuring of the college teaching force is, in this context, no different than the restructuring of professional work (including medicine and law) more broadly. Globalization, as Twigg has argued, has intensified competitive pressures and has forced entire industries to 'restructure' themselves - now including higher education and its labour force. 9

If, then, these 'new' developments are not going away and are (and will be) reshaping the faculty, what shape is it taking? On the face of it, these developments suggest nothing less than a wholesale reconfiguration of the body academic in ways that we do not yet fully comprehend. US higher education is increasingly hiring practising professionals who have not experienced extensive pre-service socialization to the academic role during traditional doctoral education. Indeed, many of these professionals may best be described as 'accidental' academics. It is increasingly hiring married women with families who are insisting on a reasonable balance between work and family-life - as indeed are the shrinking core of Millennial males.

It is increasingly hiring foreign-born and racial/ethnic minorities. It is increasingly hiring retirees from business and industry and from academic 
positions at other institutions. It is increasingly redefining traditional research university roles. We are seeing clear lines of stratification among the faculty ranks among a core permanent 'traditional' academic staff and a larger contingent staff serving more specialized functions. It is increasingly bringing into the academy a new sociological generation in terms of orientation to self, society, and work.

\section{The topography of new faculty hires}

Most fundamentally, these developments undermine the basic underlying assumption that there is, in some meaningful sense, a corporate faculty that has a fundamental unity of mission, background, motivation, and talent level. In that sense, the 'old-line' faculty no longer exists. We have rather a highly differentiated academic workforce (including an exploding number of non-faculty professionals - the fastest-growing segment of the academic workforce ${ }^{4}$ ). How can we describe the basic lines of differentiation of this new faculty workforce, those Rhoades called 'managed professionals'? ${ }^{10}$ Before we can assess how the 'old rules' are changing, we need to describe clearly the topography of the new faculty workforce. Once the cells are named, we are then in a position to assess how the various faculty sub-groups are likely to behave. That topographical mapping exercise is best applied to recent recruits to the college teaching force insofar as these represent the future of the profession - and allow us to extrapolate with greater confidence. Graphically, the topography of new recruits since at least the early 1990s is displayed in Figure 1.

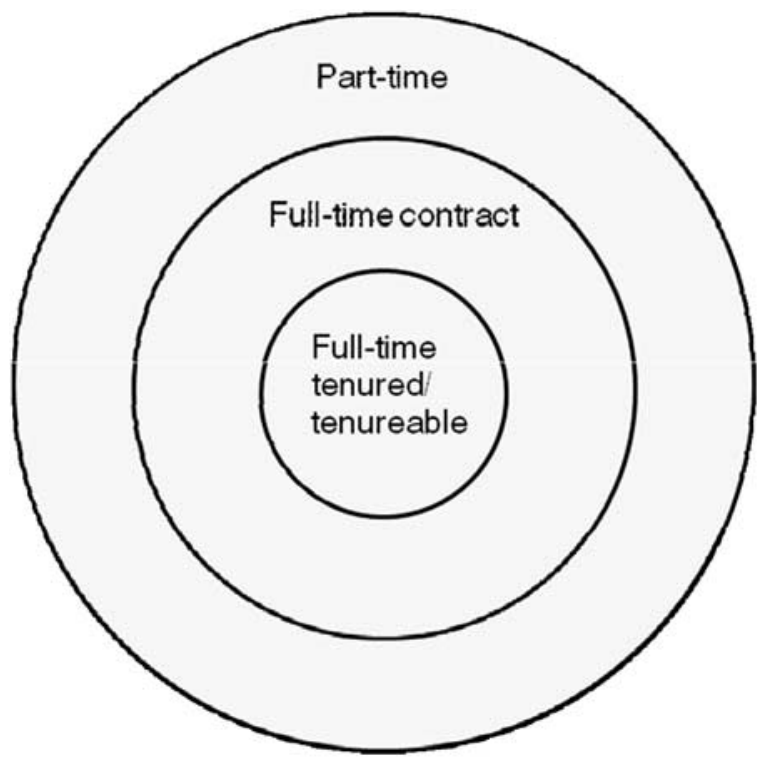

Figure 1. The topography of new faculty hires, 1993-2008 


\section{The full-time Terrain}

Among the newly hired full-timers over the past generation, the basic divide is between those 'on' and 'off' the tenure track - roughly half and half. But there are clear cleavages that criss-cross this basic one:

- the divide between men and women;

- the divide between those in the professions and those in the traditional arts and sciences;

- the divide between the younger entrants fresh out of graduate school (in their 30s) and the older entrants (frequently practising professionals in their $40 \mathrm{~s}$ or $50 \mathrm{~s}$ or 'early' retirees from business/industry or the military). Indeed, among the professionals and older new recruits are a majority of 'accidental' academics in the professions;

- the divide between those in research universities and those outside.

To begin with, what can we say about the one-quarter of the newly entering college teaching force that can be classified as traditional tenure-eligible or tenured, full-time faculty - understanding that somewhere between 40 to $50 \%$ of them are now likely to be young married women? First, it seems to the author that the most basic of the 'old rules' - that academic careerists are a 'special breed' whose unique confluence of values and interests, including intellectual interest and achievement, the quest for autonomy even at the risk of foregoing pecuniary benefit - still holds. All the available evidence suggests that those unique individuals are still being attracted to academic careers in about the same small, but unchanging, measure. Moreover, these individuals are, judging from the available recent evidence, working harder than ever (58 hours weekly in 2004 versus 53 hours in 1988) and are subject at once to increased expectations for scholarship and publication, on the one hand, and heightened expectations for teaching performance, on the other. ${ }^{3,5}$ However, what may be changing is the value orientation that mediates how these tenure-trackers fulfil these deep personal needs - and at what price. Academic women and Millennials, generally, are more oriented to family and achieving a reasonable work-life balance than has historically been the case for Baby Boomers. ${ }^{2}$ Anecdotal evidence suggests that they are less willing to sacrifice everything on the altar of work. Behavioural evidence is less clear. There are some data that suggest that recently recruited women and minority faculty are leaving academic jobs at a higher rate than white men - although the actual magnitude of that rate is not clear. ${ }^{5,11}$ Modestly higher pre-tenure attrition rates for women are likely to be more than compensated for by recruiting new members. Moreover, the restructured academic workforce provides a new diversity of opportunities including less stressful, more specialized fixed contract positions as well as a variety of part-time positions for those 
seeking alternatives to the tenure track straitjacket. This is not meant to minimize the serious equity issues that are raised by the unique situation of newly entering women faculty in the US - as elsewhere. They do indeed have a tougher road to travel with fewer immediate rewards (although compensation rates are improving slightly); and academic institutions do need to consider how they will address such issues from an equity perspective. At the same time, it is important to keep in mind that tenure-track vacancies account for a shrinking proportion of academic job openings - not quite half of the full-time vacancies over the past 15 year. Indeed, Leslie recently demonstrated using National Center for Education Statistics sources just how little the number of new tenure-track positions had grown in the US - for men as well as women - over the past generation for those under $40 .^{5}$ It is critically important to emphasize that the share of these regular full-time positions has not only declined proportionately, but that actual numbers of 'traditional' positions show almost no growth. Current supply in the aggregate is more than likely to fulfil quite adequately that reduced demand - assuming that the old-line faculty do not, as a group, retire all at once (certainly an unlikely scenario!). More troubling - and receiving much less attention - are the changing prospects of foreign-born faculty, especially Asian men in the natural sciences and engineering. While US graduate programmes in these disciplines have, for at least the past quarter-century, been stocked by foreign-born scholars, there is new evidence suggesting that young scholars who once completed their doctorates in the United States and routinely stayed there to pursue academic and research careers are now less likely to come (a function at least in part of post-9/11 immigration restrictions) and are increasingly returning home to pursue academic careers in the rapidly developing higher education systems of their home countries. $^{12}$ Per capita research and development expenditures are increasing much more rapidly in China and other parts of Asia than in the United States. ${ }^{13}$ Indeed, while the United States still maintained a global lead in production of scholarly papers and research, the centre of gravity is discernibly shifting as by far the greatest growth in scholarly production moves to Asia. ${ }^{13}$ While the magnitude of this reversal of the 'brain drain' is not yet clear, the emerging signs are unmistakable, especially among Chinese academics. Moreover, there is no evidence whatever that the proportion of native-born American students in these fields is on anything but the continued wane. ${ }^{5}$ Future prospects for foreign-born faculty underline the larger issue of discipline-specific variation in the actual numbers and proportionate representation of tenure-track and tenured faculty positions. Leslie recently examined disciplinary differences in the proportion of tenure-track versus fixed-term positions between 1988 and 2004. ${ }^{5}$ He reported a clear bifurcation between those fields that showed continued growth in tenuretrack positions and those that were growing primarily through the proliferation of fixed-contract positions. Generally, the natural sciences were the only group of 
disciplines showing considerable growth in tenure-track appointments - although they also grew in the number of contingent appointments. The health sciences, the humanities, and education, on the other hand, grew almost entirely in terms of contingent positions while the number of tenured positions actually declined. Faculty in the 'high-tenure gain' fields have higher pay, lower undergraduate teaching loads, and produce more publications than faculty in 'low-tenure-gain' fields. They are also more likely to receive research funding and spend more time on research. Moreover, the fields that have gained in the proportion of tenured/ tenurable positions have tended to reduce reliance on part-time faculty while those who have lost tenured faculty have come to rely increasingly on part-time faculty.

These analyses suggest four things:

(1) The traditional tenured/tenurable faculty is shrinking and is likely to continue to do so. The demand for tenured/tenure able faculty is actually declining; and available supplies, despite some minor downturn in $\mathrm{PhD}$ production, seem likely more than adequate to meet demand. Moreover, currently practising professionals and retirees seeking second careers constitute new and promising sources of supply.

(2) Developments are increasingly uneven across fields. Certain fields in the natural sciences and engineering are certain to require an increased need for recruitment for tenure-track positions; most other fields are decreasing their recruitment of tenurable/tenured traditional faculty. The American academic landscape is increasingly differentiated by academic field or groups of academic fields stratification lines that began to be drawn in the 1980s have now taken a second-order leap forward. ${ }^{14}$ Very different recruitment and retention policies will be required in these situations.

(3) Foreign-born scholars have, over the past 20 years, played an important role in American graduate education in the natural sciences and engineering and have allowed the national scientific research enterprise to be adequately staffed. There are emerging signs that over the next generation there will be increasing competition for that supply from rapidly developing higher education systems, especially in Asia (that is, China's world-class universities initiative). In the context of current federal immigration policies, the recruitment of foreign-born scholars becomes particularly problematic.

\section{The contingent faculty}

What can we say about the one-quarter of new academic positions that are fixedterm contract positions? In the first place, it is helpful to recap the major subcategories that exist within this broad area: full-time faculty in the professions, 
especially the health professions, who are 'accidental' academics; women faculty who deliberately seek more circumscribed positions that do not involve open-ended research commitments (in some cases, moving from a tenure-track to a fixed-contract position or even to a part-time position, typically for family reasons); and aspiring, full-time tenure track faculty, males as well as females, who have been unable to land tenure-track positions, especially in certain 'oversupplied' fields such as the humanities and education. Recruitment and retention issues, I would argue, vary considerably depending on which of these three sub-groups one is talking about. The 'aspiring tenure-trackers' are the most single-mindedly motivated of the three subgroups: while some may abandon the hope of a traditional academic career at some point (and economic concerns are likely to accelerate that 'tipping point'), they typically represent that 'special breed' of individual for whom academic work represents a rare occupational opportunity to fulfil deep personal needs. While some women may fall into this category of aspirants, there are many more who can be classified as 'life balancers' for whom such term-limited and work-circumscribed positions are indeed a positive inducement to a species of academic life that minimizes its greatest disadvantages/costs. For those new faculty recruits who have retired from a first career and who are seeking renewal or reinvention in a second career (often coming with attractive pension in hand), contingent academic life may offer just the right blend of meaning and (marginally acceptable) compensation. The critical supply implications here tend to be field-specific. That is, there are a handful of fields where a significant segment of the entry-level academic track is functionally specialized, fixed-contract positions. They include English, foreign languages, mathematics, basic business courses, introductory general education requirements (drawing on social science and humanities faculty), and certain professional fields, including the health sciences. While American higher education may not, in the short or intermediate term, be in danger of 'running out' of such individuals, there are troubling long-term implications for the survival and prosperity of these fields for whom academic careers have historically provided a modal venue.

The sub-group of professional field faculty - the 'accidental' academics - are probably the most challenging of the three sub-groups in terms of recruitment and, especially, retention. Many of these individuals will have been practising their profession before assuming a faculty position, are doing so while concurrently holding a faculty position, or will return to professional practice after a stint in a faculty position. Issues of competitive compensation will be greatest here. Then, of course, there are the part-time faculty. They rarely constitute much of a recruitment problem - although this obviously varies by field and by geographic location (relatively easy in the major urban areas, much more difficult in rural areas). Retention can be a problem, but the available data suggest that nearly one tenth of part-timers are actually tenured and as much as half may be classified as long-term part-timers - that is, individuals who teach one or two 
courses a year over a significant stretch of time. It is important to be clear that the labour market for contingent faculty is likely quite different than that for tenuretrack faculty. ${ }^{2}$ It may be local or regional, but is rarely national or international; or, as Twombly has described it in relation to the hiring of full-time tenure-track faculty at major community colleges, 'recruit nationally, but hire locally or regionally'. ${ }^{15}$ This means that institutions may not be self-consciously seeking the absolute 'best and brightest' in filling different sorts of faculty positions, so much as seeking to match the requirements of a particular position (which may, for example, focus on clinical teaching) to the talents of a particular individual. Many, depending on location, will test the local and regional market - even while placing advertisements in the national media. It is a critical piece of reality testing that only a bare majority of vacancies may be filled these days by national search and national hiring processes focused on a prospective recruit's scholarly accomplishments and potential.

\section{What is the relevance of this portrait of a differentiated US academic workforce to Europe?}

To what extent, and in what ways, does the portrait of diversification of the American academic workforce have any relevance to the national systems of Europe? At what level of generalization? Or detail? Is the American case simply an idiosyncratic aberration, an isolated curiosity - given the great differences between the American system and most of the systems of Europe? And even if there be some isomorphism between trends in the US and various European countries, are these trends equally powerful in their system effects?

The most basic point of departure in addressing these questions is to pose two more focused questions: to what extent are the same forces or drivers operating on the several national systems similar or different? And to what extent are the trends that we have identified replicated in one or more European countries?

However similar in appearance, are the trends equally pre-emptive and do they impact the general system in the same way? Are they driving change in the system? Or are they still merely peripheral? And, if the latter, for how much longer? Or, under what conditions might they become less peripheral? ${ }^{16}$

\section{Isomorphism in drivers}

Most generally, of course, developed nations across the globe are subject to the same competitive pressures of a globalized, knowledge-based economy as the US, including

- the need to focus on extending tertiary education as a vehicle for longterm human resource development; 
- the need to 'manage' the costs of expanded tertiary education through the development of new models that are less labour intensive than the traditional face-to-face classroom model or involve lower 'fixed costs' and/or through the development of new financing arrangements, i.e. privatization;

- constraints of increasing life expectancies across the developed world and the growth of the post 60 demographic group (the 'surging' seniors) simultaneously increasing competing public sector demands (vis-à-vis tertiary education) for public pensions and health care funding advanced by an increasingly politically powerful segment of the population - and limited available public resources for higher education.

These developments, of necessity, require some kind of re-structuring of faculty work as the major component of higher education costs. Such restructuring can include tinkering within the context of current models of academic work, e.g. by increasing teaching loads or number of students taught as a means of exploiting current capacity to the limit or even overloading current capacity; such mechanisms as 'performance funding' wherein the same (or usually fewer) resources are allocated on a performance basis - presumably targeting resources to where they have the most impact; establishment of parallel academic universes (in the social change literature, the establishment of alternative institutions), wherein contract or other temporary academic personnel assume a significant share of the workload - thus reducing the 'fixity' of academic personnel costs at traditional institutions. At the extreme, this might include the establishment of entirely 'new' non-traditional institutions, e.g. the UK's Open University, or the wholesale elimination of academic tenure or the civil service status of academic professorial personnel as in the case of the UK (and almost the case in Japan).

In Japan, the introduction of the fixed contract system (as an alternative to civil servant status) has proceeded 'voluntarily' by the vote of individual faculties on the basis of 'incentives' created by the MOE. However voluntary, the progress has nonetheless been inexorable and has been consummated most fully at the major national universities, e.g. Tokyo. In other contexts (the Netherlands), legislative initiatives have been advanced and to date rebuffed. ${ }^{17}$

\section{Common trends in the European context}

Not only are some of the same 'drivers' at work in the European context, but these drivers have expressed themselves in similar trends and developments in the higher education system. These include:

- a trend to decentralizing national government control to institutional academic management, reinforcing local discretion in academic 
appointments and workload - albeit usually within specified national parameters - the sort of decentralization (although not quite as radical) that in the US has led to 'innovative' staffing configurations and their rapid spread through the system;

- a trend toward increasing pressures on faculty workload, which appear to this point not to have reached a level to where actual 'restructuring' is required (running out of slack organizational and individual faculty capacity to accommodate increased workload);

- the establishment of a variety of parallel academic appointment tracks, that usually involve increased specialization in academic tasks - either teaching only or research-only appointments - and are associated with a shrinking core of traditional full-time, permanent and research oriented faculty;

- the disproportionate growth of national tertiary systems outside the traditional research university sector that provide alternative, nonresearch career tracks;

- the increasing feminization of academic workers, especially newer recruits to academic careers, although (a) the pace varies widely among European countries and tends not to be on the scale of the US; and (b) it is not clear to what extent they hold new kinds of dispositions and values toward work-family life balance as do their counterparts in the US. They do, however, as in the US, appear to be represented disproportionately among the 'new' kinds of academic appointments.

There is, of course, considerable diversity within the European community. To an outside (non-European) analyst, that diversity encompasses at least three broad patterns. First, there are the countries of southern Europe (principally Italy, Spain and Portugal) representing the most traditional systems of academic staffing, and while not immune (impervious) to the trends we have identified, nonetheless experience them as largely 'peripheral' to what remains the modal traditional system. Second, there are the Nordic countries (Sweden, Norway, Finland, Denmark) who have retained much of their traditional staffing patterns and especially the status of the professor as 'civil servant' - largely it would appear as a function of the influence of the powerful trade union. Finally, there is the vast middle (Germany, Netherlands, France, the UK) where the trends we have identified are more disruptive of the traditional order, especially in the case of the UK.

This admittedly impressionistic portrait suggests two broad differences between the United States and continental Europe. In the first place, developments in the US appear to have gone further and had a larger impact on the character of the system thus far than in Europe. There are certain characteristics of continental Europe that will militate against as rapid a rate of change as in the 
US, these being the basic power of academic tradition (Italy, Spain), the more powerful role of national government (even if decentralization has been proceeding in several countries), and the political power of trade unions in resisting the negotiation away of the professorate's civil services status. That being said, the winds of change are clear and being broadly felt - on both sides of the Atlantic. As higher education globalizes and increases competitive pressures across as well as within national boundaries, these winds will only intensify and particularly as economic imperatives gain in ascendance, they are likely to prevail. A strong tradition of government control will not, by itself, cut the winds - witness the UK and Japan and the demise of tenure. Will the power of tradition and the trade unions prevail? Will new developments related to economic regionalization, specifically, the Bologna Process, expand national academic labour markets to regional, pan European ones?

\section{A final word}

The above description and analysis suggests that the academic profession in the United States as we have known it since the Second World War - a relatively homogeneous workforce united by a common background, a common mission, a common career trajectory, albeit with significant variation among institutional types and academic fields - has transformed itself, perhaps under our collective radar, into a highly differentiated workforce segmented by diverse backgrounds, career trajectories, motivation, talents, and work roles. The heretofore (historic) core of that workforce, the tenured and tenure-track faculty, is shrinking overall and subject to increased workload pressures. That shrinkage varies widely by academic field, creating very different market situations for the traditional faculty labour. While these new conditions pose challenges to the large entering cohort of women faculty and Millennials, and may indeed be exacerbating attrition among these groups, entirely new sources of supply - practising professionals and retired individuals seeking second careers - are emerging that nicely match emerging curricular needs/student preferences in ways that promise to offset any modest attrition increases among traditional new recruits. This differentiation of the profession represents an irreversible structural shift in response to larger economic forces transforming the world of work. The notion of academics as a 'cohesive group' united by a common pre-service socialization experience will become increasing limited in its application to a shrinking core. Academic careers are becoming less exclusive and less subject to the rules of inertia. If, in some respects, the shaping influence of institutional type becomes attenuated as a 'research and publication' culture extends beyond research universities to many four-year institutions, that influence of academic field becomes stronger as disciplinary markets Balkanize ever further along the lines of 'market' value. 
We will need to think about the academic labour market in much more fieldspecific and nuanced ways. A crisis in one area may not be a crisis in all - but depending on its specific location, a crisis nonetheless. American colleges and universities will be weighing to what extent they can recruit and manage a highly differentiated workforce that supports their institutional mission without weakening the traditional core of their academic staffs - the tenured/tenurable faculty.

If American universities face one imperative in the short and medium term, it is to publicly and deliberatively come to grips with the new academic order. Institutions need to think long and hard - and collectively - about what kinds of faculty roles support which aspects of their mission. To what extent can the requirements and contours of traditional tenurable positions be modified to accommodate the new Millennial generation of academic women?

To what extent ought accommodation to be achieved not by modifying traditional faculty roles, but by constructing and strengthening new types of more specialized roles? What is the right proportion of faculty appointments to optimize institutional mission and individual career development and satisfaction? To the extent that the academic workforce is diversifying its background and pre-service socialization, what new structures will institutions need to design in order to socialize an increasingly heterogeneous group of professionals to some set of traditional academic norms? Or, to what extent should the traditional norms that bound the tenured faculty simply be allowed to disintegrate? Which norms or elements are mission critical - in the short and or long-term? Which are simply gratuitous vestiges of an old order?

A European colleague assured me that significant social developments in the US arrive at European shores within about six years of their American debut. Strictly speaking, he was referring to secondary school shootings and fast food restaurant chains. Over the next generation, higher education may find its way into the pantheon of illustrative cases!

\section{Acknowledgement}

The author acknowledges the support of the Fondazione Compagnia di San Paolo.

\section{References}

1. L. Wolf-Wendel, S. Twombly and S. Rice (2003) The Dual-Body Problem: Dual Career Couple Hiring Practices in Higher Education (Baltimore: The John Hopkins University Press).

2. N. Howe and W. Strauss, with R. B. Matson (Illustrator) (2000) Millennials Rising: The Next Great Generation (New York: Vintage Press).

3. J. Schuster and M. Finkelstein (2006) The American Faculty: The Restructuring of Academic Work and Careers (Baltimore, MD: Johns Hopkins University Press). 
4. C. Frances (1998) Higher education: enrollment trends and staffing needs. TIAA-CREF Research Dialogues, 55(March), 1-23.

5. D. Leslie (2007) The reshaping of America's academic workforce. TIAACREF Research Dialogues, 87(March), 1-23.

6. R. Chait (2002) Questions of Tenure (Cambridge, MA: Harvard University Press).

7. M. Finkelstein (2003) The morphing of the American academic profession. Liberal Education, 89(4), 6-15.

8. M. Trow (1973) The transition from elite to mass to universal higher education. In: Policies for Higher Education, from the General Report on the Conference on Future Structures of Postsecondary Education (Paris: OECD), pp. 55-101.

9. C. Twigg (2002) The impact of the changing economy on four-year institutions of higher education: the importance of the internet. In: The Knowledge Economy and Postsecondary Education: Report of a Workshop, edited by P. Graham and N. Stacey (Washington, DC: National Academy Press), pp. 77-104.

10. G. Rhoades (1998) Managed Professionals: Unionized Faculty and Restructuring Academic Labor (Albany, NY: State University of New York Press).

11. C. A. Trower and R. P. Chait (2002) Faculty diversity: too little for long? Harvard Magazine, 104(March/April), pp. 33-38, cited by J. M. Gappa,

A. E. Austin and A. G. Trice (2007) Rethinking Faculty Work (San Francisco: Jossey-Bass).

12. S. Hong (2008) Development of the Academic Profession in China: Results of a National Survey. Paper presented at an International Conference on the Changing Academic Profession (co-sponsored by Hiyajima and Hiroshima Universities), Hiroshima, Japan, 28-30 January.

13. W. K. Cummings (2008) The Context for the Changing Academic Profession: A Survey of International Indicators. Keynote address at the International Conference on the Changing Academic Profession, Hiroshima, Japan, 28-30 January.

14. H. Bowen and J. Schuster (1986) American Professors: A National Resource Imperiled (New York: Oxford University Press).

15. S. Twombly (2005) Values, policies and practices affecting the hiring process for full-time arts and science faculty in community colleges. Journal of Higher Education, 76(4), 423-447.

16. D. B. Johnstone (2003) The International Comparative Study of Higher Education: Lessons from the Contemplations of How Others Might See Us (Washington, DC: Forum for the Future of Higher Education and the National Association of College and University Business Officers).

17. J. Enders (ed.) (2001) Academic Staff in Europe: Changing Contexts and Conditions (Westport, CT and London: Greenwood Press).

\section{About the Author}

Martin Finkelstein is professor of Higher Education at Seton Hall University, South Orange, NJ. He received his PhD from the State University of New York at 
Buffalo in 1978. Since then, he has taught at the University of Denver and Teacher's College, Columbia University and has served as a Visiting Scholar at the Claremont Graduate University, the Research Institute for Higher Education, Hiroshima University, Japan, and as a Fulbright Senior Specialist and Visiting Professor in the Faculty of Education, University of Hong Kong. Between 1989 and 1997, he served as the Executive Director of the New Jersey Institute for Collegiate Teaching and Learning, a publicly financed staff development initiative of the state of New Jersey. He is the author of The American Academic Profession (Ohio State University Press, 1988) and The New Academic Generation (with Robert Seal and Jack Schuster, Johns Hopkins University Press, 1998). His recent book with Jack Schuster, The American Faculty: The Restructuring of Academic Work and Careers, was published in 2006 by the Johns Hopkins University Press. In 2006-2007, he collaborated with William Cummings, George Washington University, in completing the US version of the Changing Academic Profession survey. 